\title{
Family and friends' fears of recurrence: impact on the patient's recovery after subarachnoid hemorrhage
}

\author{
Clinical article
}

\author{
Judith Covey, Ph.D., ${ }^{1}$ Adam J. Noble, Ph.D., ${ }^{2}$ and Thomas Schenk, Ph.D. ${ }^{3}$ \\ ${ }^{1}$ Department of Psychology, Durham University, Stockton-on-Tees; ${ }^{2}$ Department of Clinical Neuroscience, \\ Institute of Psychiatry, King's College London, United Kingdom; and ${ }^{3}$ Department of Neurology, University \\ of Erlangen-Nürnberg, Erlangen, Germany
}

Object. Patients with subarachnoid hemorrhage (SAH) and their close friends and family may be excessively fearful that the patient will have a recurrence, and such fears could play a critical role in the poor recovery shown by many patients The authors examined whether these fears could account for significant variance in psychosocial outcomes.

Methods. The authors prospectively studied a sample of 69 patients with SAH alongside their spouse, other family member, and/or close friend identified as their significant other (SO). The patient/SO pairs were assessed at 13 months postictus for their fears of recurrence and for health-related quality of life on the 8 domains of the 36-Item Short Form Health Survey.

Results. The SOs were found to be significantly more fearful of SAH recurrence than the patients. The SO's fears also explained unique variance in the patient's recovery on 4 of the 36-Item Short Form Health Survey domains over and above the patient's own fears, demographic and/or neurological variables, and the patient's history of psychiatric or neurological problems. The domains affected reflected activity-based and functional aspects of the patient's quality of life as opposed to more general characteristics of their emotional well-being or physical health state.

Conclusions. The patient's recovery may be compromised if their spouse, close family, and/or friends are excessively fearful about their suffering a recurrence. Perhaps the SO's fears cause them to be overprotective of the patient and to restrict their day-to-day activities. Attention must therefore be given to the experience of having a loved one suffer from an SAH, and alleviating the caregiver's fears could help to promote a better outcome for the patient. (http://thejns.org/doi/abs/10.3171/2013.5.JNS121688)

KEY WORDS • subarachnoid hemorrhage $\bullet$ caregiver $\bullet$ psychosocial domain
recovery $\bullet$ fear $\bullet$ recurrent hemorrhage

$\mathrm{P}$ ERSONS who survive a spontaneous SAH often experience a poor psychosocial outcome even after good neurological recovery. Their HRQOL is often found to be impaired in comparison with both general population norms ${ }^{8,11,14,15,17,19,35,37}$ and other patient groups. ${ }^{22,24,30}$ How patients can be supported to achieve a better psychosocial outcome remains unclear, but a range of factors might be important, including the support and care that they receive, not only from health professionals but also from their SOs - that is, their spouses, partners, and close relatives. ${ }^{39}$

Abbreviations used in this paper: $\mathrm{HRQOL}=$ health-related quality of life; $\mathrm{PD}=$ Parkinson disease; $\mathrm{SAH}=$ subarachnoid hemorrhage; SF-36 = 36-Item Short Form Health Survey; $\mathrm{SO}=$ significant other; WFNS $=$ World Federation of Neurosurgical Societies.
However, many SOs experience symptoms of psychological distress including anxiety, ${ }^{14,31}$ depression,, 52 stress, ${ }^{2,12,13,23,30,32}$ and sleep dysfunction, ${ }^{23}$ which may affect their ability to care for the patient. More specifically, despite a further hemorrhage being rare, $7,25,36,40,43$ many SOs of patients with SAH report feelings of anxiety and uneasiness over their loved one suffering a recurrence..$^{14,38}$ These elevated fears could further hamper the patient's psychosocial recovery if SOs react by overly restricting the patient's everyday activities. There is some evidence suggesting that this might occur, with research by Hop et al. ${ }^{14}$ finding that 4 months following the SAH, some SOs remained reluctant to leave the patient alone in case another hemorrhage occurred. Of course, the patient's own fears of recurrence $1,3,4,16,20,21,24,38$ might produce similaror even bigger-restrictions. Seemingly as a consequence 


\section{Fears of recurrence and impact on recovery from SAH}

of their own fears, patients with SAH can place restrictions on their day-to-day lives, such as not participating in certain activities like driving, lifting, using machinery, sexual intercourse, and physical exertion. .,3,14,21,41 $^{-1}$

It is unknown, however, whether the fears of either the patients or their SOs contribute in any way to the patient's psychosocial recovery-and if they do, which domains of quality of life are most affected. This paper addresses this gap in the literature by presenting data that show the relative contributions of both the patient's and the SO's fears of recurrence on patient psychosocial recovery measured at approximately 13 months postictus. The effects on different domains of quality of life were compared using the SF-36 measure of HRQOL, ${ }^{42}$ which provides an 8-domain profile of functional health and well-being in the following domains: 1) physical functioning; 2) role limitations due to physical problems; 3) bodily pain; 4) general health perceptions; 5) vitality/energy; 6) social functioning; 7) role limitations due to emotional problems; and 8) mental health (Fig. 1).

Our first aim was to establish whether the patients and SOs shared the same fears of SAH recurrence. Given that the patient/SO pair have experienced the same traumatic event, we might expect that their fears are relatedthat is, patients who are most fearful of SAH recurrence are paired with SOs who are also most fearful. However, prior SAH studies have shown that SOs can have higher levels of emotional distress than the patient. ${ }^{5,14,32}$ Therefore, we tested whether the SOs were more or less fearful of SAH recurrence than the patients themselves. We also compared their fears of SAH recurrence with their fear levels regarding the possibility of the patient's developing 3 other health problems (PD, heart attack caused by coronary artery disease, and lung cancer). We were interested in whether any differences found between the SO's and the patient's fear levels were specific to SAH recurrence or whether they generalized to other types of health problems.

Our second aim was to use regression modeling to test whether the SO's fears could make a unique contribution to the patient's psychosocial recovery over and above the patient's own fears of recurrence. The analysis

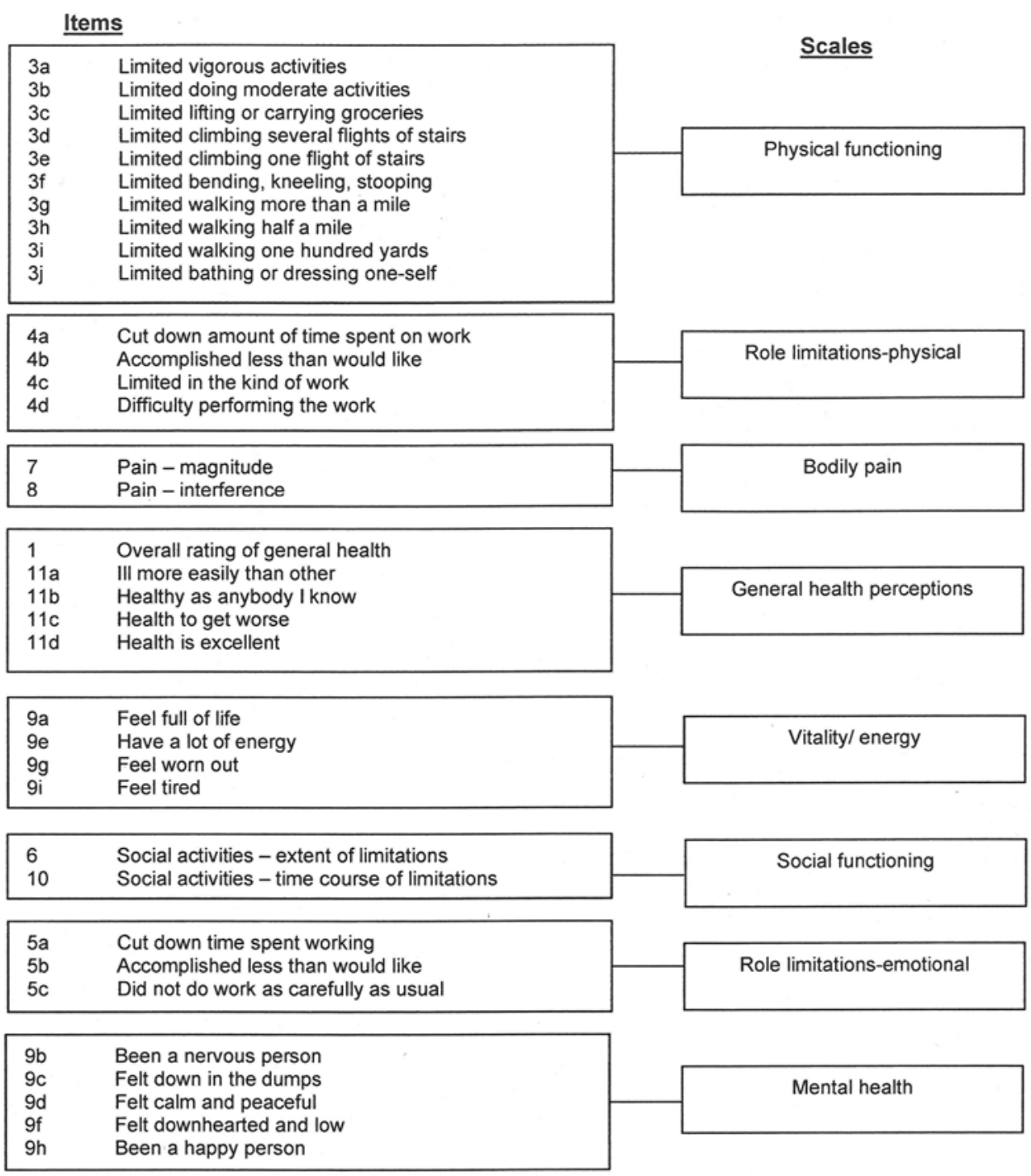

Fig. 1. Schematic structure of the domains in the SF-36 questionnaire used in this study. 
also controlled for the patient's age, sex, initial clinical grade of SAH, and premorbid history of psychiatric or neurological problems. We were particularly interested in exploring which, if any, of the 8 SF-36 domains of the HRQOL were most affected by the patient's own and the SO's fears of recurrence.

\section{Methods}

\section{Study Participants}

A group consisting of 69 patients who had suffered a spontaneous SAH and their SOs was enrolled in this prospective study and was assessed an average of 13.2 months postictus (SD 1.43 months). All patients were noninstitutionalized first-time sufferers of SAH who had been admitted to Newcastle General Hospital or James Cook University Hospital, Middlesbrough, between May 2005 and August 2006 and were recruited as part of a wider study on outcome after SAH. ${ }^{26,27}$ The diagnosis was confirmed by CT scan or, if scanning was negative, by the presence of blood or blood products in the CSF. Aneurysms were demonstrated by CT, MR, or catheter angiography. The SOs were approached through the patients, who passed an invitation to the SO if they wished him or her to participate. An SO was defined as the person the patient felt closest to and who was the most involved in providing informal support after the illness.

Multicenter approval was awarded by the Central Manchester Research Ethics Committee. Informed consent was obtained from all participants.

\section{Measures Used in the Study}

Fear Ratings. Each member of the patient/SO pair independently rated how much they feared the patient suffering from 4 different health problems in the future: another SAH, lung cancer, PD, and a heart attack caused by coronary artery disease. A 5-point rating scale developed for this study $(0=$ no fear, $4=$ extreme fear $)$ was used. We asked the patient/SO pairs to rate their fears of the patient suffering from 3 health problems unrelated to SAH to establish whether any differences or similarities that we might observe between their fear levels were unique to the SAH event.

Quality of Life. The SF-3642 was used to assess the patient's HRQOL across 8 domains: 1) physical functioning; 2) role limitations due to physical problems; 3 ) bodily pain; 4) general health perceptions; 5) vitality/energy; 6) social functioning; 7) role limitations due to emotional problems; and 8) mental health.

\section{Data Analysis}

Pearson correlation coefficients were used to examine the degree to which the fear ratings of the patient/SO pairs were related, and mean differences between their ratings were tested for significance by using paired t-tests. These analyses were conducted for each of the fear ratings (that is, SAH, heart attack, lung cancer, and PD).

Multiple regression analysis was used to determine the extent to which the fears of SAH recurrence of each member of the patient/SO pair uniquely contributed to the psychosocial recovery of the patient on each of the 8 SF36 HRQOL domains. The regression models controlled for the patient's age, sex, the initial clinical grade of the condition according to the WFNS scale, ${ }^{9}$ and whether the patient reported a history of a diagnosed psychiatric illness or neurological condition prior to the hemorrhage. Although the sample size was quite small, the case/variable ratio of 69:7 was close to the commonly reported rule of thumb that specifies 10 cases per variable to produce a reliable regression model..$^{10}$ Moreover, an a priori calculation performed using G*Power 3.1.5 (www.psycho. uni-duesseldorf.de/abteilungen/aap/gpower3) confirmed that the study was powered sufficiently to demonstrate medium effect sizes (that is, Cohen $\left.\mathrm{f}^{2}=0.117\right)^{6}$ for significance tests of the increase in variance that each predictor could add to the model.

\section{Results}

\section{Patient/SO Pair Sample}

The demographic characteristics of the 69 patient/ SO pairs are shown in Table 1. As shown, the SOs were slightly more likely to be female and, on average, were just over 2 years younger than the patients, but the difference in age was not statistically significant $(\mathrm{t}(68)=1.87$, p $=0.066$ ). A large majority of patients were initially graded as either WFNS Grade I or II (81.1\%) and therefore presented with high Glasgow Coma Scale scores $(\geq 13)$ and without focal neurological deficits.

\section{Patient Versus SO Fear Ratings}

Table 2 shows the correlations between the patient's fears and those of the SO. Fears of SAH recurrence were unrelated, with no evidence that the patients who were most fearful of SAH recurrence were paired with the SOs who were also most fearful. Although fear of the patient's developing lung cancer were more likely to be shared (the

\section{TABLE 1: Characteristics of the 69 patient/SO pairs}

\begin{tabular}{|c|c|c|}
\hline Characteristic & Patients w/ SAH & SOs \\
\hline \multicolumn{3}{|l|}{ age in yrs } \\
\hline mean $\pm S D$ & $53.7 \pm 10.4$ & $51.0 \pm 14.3$ \\
\hline range & $28-80$ & $19-79$ \\
\hline \multicolumn{3}{|l|}{ sex } \\
\hline$\%$ female & 53.6 & 60.9 \\
\hline$\%$ both male & 1.4 & \\
\hline$\%$ both female & 15.9 & \\
\hline$\%$ mixed & 82.6 & \\
\hline \multicolumn{3}{|l|}{$\%$ w/ WFNS grade } \\
\hline I & 71.0 & \\
\hline$\|$ & 10.1 & \\
\hline III & 7.2 & \\
\hline IV & 11.6 & \\
\hline history of psychiatric illness & 28.9 & \\
\hline history of neurological condition & 30.4 & \\
\hline
\end{tabular}


TABLE 2: Correlations and differences between patient/SO pairs' fears of the patient suffering from 4 different health problems in the future*

\begin{tabular}{lcccc}
\hline \multicolumn{1}{c}{ Condition } & $\begin{array}{c}\text { Pearson } \\
\text { Correlation }\end{array}$ & Patients & SOs & $\begin{array}{c}\text { Paired } \\
\text { t-Test }\end{array}$ \\
\hline SAH recurrence & 0.077 & $1.48 \pm 1.49$ & $2.04 \pm 1.39$ & $-2.37 \dagger$ \\
lung cancer & $0.358 \mp$ & $1.24 \pm 1.17$ & $1.36 \pm 1.25$ & -0.72 \\
PD & -0.024 & $0.88 \pm 1.11$ & $0.88 \pm 1.08$ & 0.00 \\
heart attack & 0.097 & $1.70 \pm 1.15$ & $1.56 \pm 0.99$ & 0.77 \\
\hline
\end{tabular}

* Fear ratings for patients and SOs are expressed as the mean \pm SD.

$\dagger p<0.05$.

$\ddagger p<0.01$.

correlation shown in Table 2 is statistically significant), fears of PD and heart attack were not correlated.

The mean values of the fear ratings $\pm \mathrm{SD}$ are also shown in Table 2. The first finding to note is that there was no average tendency for patients or SOs to be more or less fearful of the patient suffering from lung cancer, PD, or a heart attack. In stark contrast, however, the SOs were significantly more fearful than the patients were themselves of SAH recurrence. Further examination of the distribution of responses showed that this difference was largely produced by a lower proportion of "no fear" ratings in the SOs rather than a higher proportion of "extreme fear" ratings: "no fear" ratings were given by $34.3 \%$ of patients and $17.4 \%$ of SOs, whereas at the other end of the scale "extreme fear" ratings were given by $18.8 \%$ of patients and $21.7 \%$ of SOs.

\section{Role of Patient/SO Fears in Explaining HRQOL}

The estimated regression coefficients are reported in Table 3 for each of the 8 SF-36 domains of quality of life. The combined effects of the predictors explained between 18\% (bodily pain) and 28\% (social functioning and role limitations-emotional) of the variance in HRQOL. However, the contributions of the individual predictors varied across the 8 domains. Neurological history explained the largest amount of variance in general health perceptions $\left(\Delta \mathrm{R}^{2}=11.8 \%\right)$ and role limitations-physical $\left(\Delta \mathrm{R}^{2}=13.8 \%\right)$. Psychiatric history explained up to $10 \%$ of the variance in social functioning $\left(\Delta \mathrm{R}^{2}=9.9 \%\right)$, role limitations-emotional $\left(\Delta \mathrm{R}^{2}=7.1 \%\right)$, and mental health $\left(\Delta \mathrm{R}^{2}\right.$ $=5.6 \%$ ). It is notable that the fears of the SOs rather than the fears of the patients themselves explained significant variance in 4 domains: social functioning $\left(\Delta \mathrm{R}^{2}=8.1 \%\right)$; general health perceptions $\left(\Delta \mathrm{R}^{2}=7.7 \%\right)$; physical functioning $\left(\Delta \mathrm{R}^{2}=7.4 \%\right)$; and role limitations-emotional $\left(\Delta \mathrm{R}^{2}\right.$ $=5.1 \%$ ). In contrast, the only coefficient close to significance for the patient's own fears was for role limitationsemotional $\left(\Delta \mathrm{R}^{2}=4.1 \%, \mathrm{p}=0.074\right)$.

\section{Discussion}

This paper has demonstrated that patients with SAH and their SOs do not share the same fears of recurrence. Most notably, the SOs were significantly more fearful than the patients, although the patients and SOs were
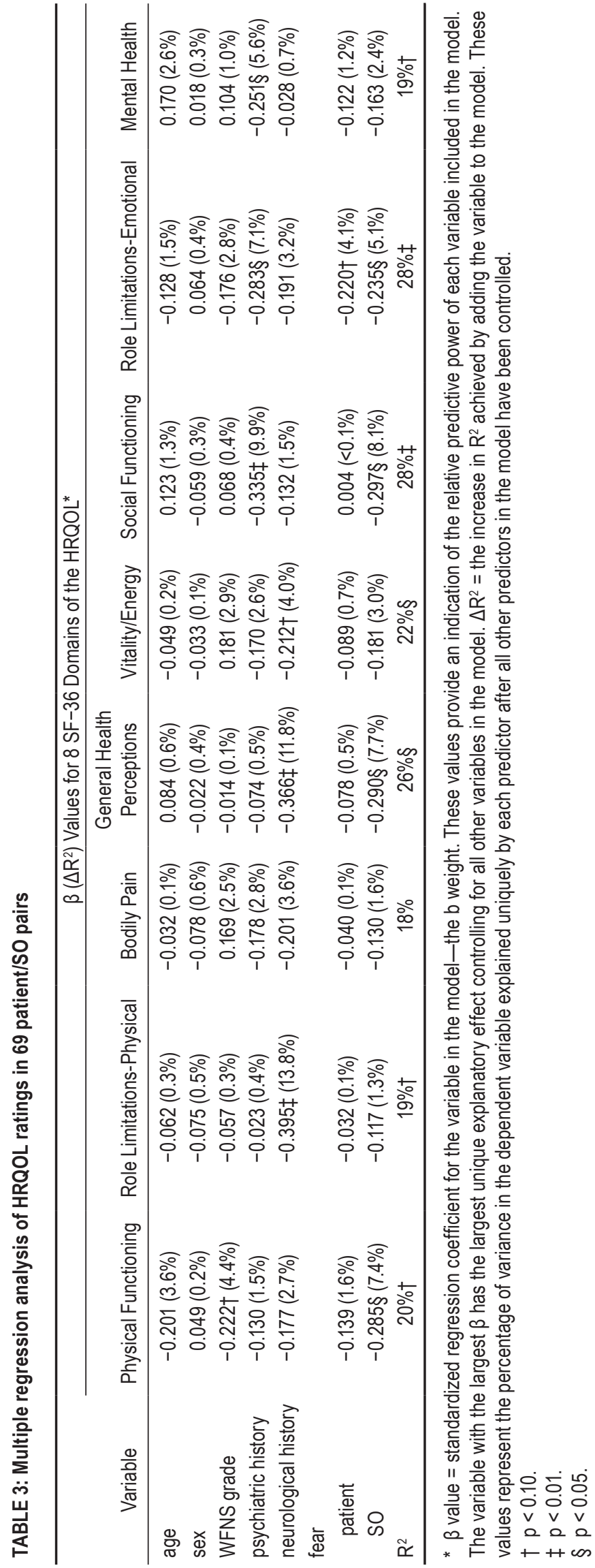
equally fearful of the patient suffering from a heart attack, lung cancer, and PD. If this finding can be replicated in further samples of SAH patients and their SOs, we would need to look beyond stable dispositional factors such as age, sex, personality, and dispositional optimism to explain the difference. ${ }^{34}$ Whatever is causing the difference, the lack of correspondence between the patient's and SO's fears of SAH recurrence turns out to be a result of great significance when we examine the findings from the regression analyses.

Specifically, only the SO's fears explained more than $5 \%$ of variance in any of the domains of the patient's HRQOL. The patient's own fears explained no significant variance, and the contribution was typically negligible (that is, less than $1 \%$ of variance). The only domain where the patient's own fear rating was close to the threshold for significance was in role limitations-emotional, where approximately $4 \%$ of the variance was explained. The patient's fears of recurrence appeared to interfere a little with their work and daily activities. However, the SO's fears of recurrence interfered more-not only with the patient's work and daily activities (role limitations-emotional), but also with their social activities (social functioning), ability to undertake moderate or vigorous physical activities (physical functioning), and ratings of health in general (general health perceptions). The SO's fears made no significant contribution, however, to the patient's level of anxiety or depression (mental health), how worn out (vitality/energy) or in pain they were (bodily pain), or the effects that the patient's health was having on their work and daily activities (role limitations-physical).

Although further research is needed to explore why the SO's fears impact the patient's recovery, this pattern of findings suggests that the effect might stem from a desire to protect the patient from coming to any harm. Although SOs may be acting with the best of intentions, a desire to protect the patient could mean that they are inadvertently placing restrictions on what the patient does both physically and socially. Perhaps SOs help them a bit too much with everyday physical tasks and limit social activities, thereby slowing down physical rehabilitation, ability to return to work, and participation in daily and social activities.

In accordance with a previous meta-analysis we conducted, ${ }^{28}$ the present study also found that demographic and neurological information on the patient explained no significant variance in any of the domains of the patient's HRQOL: the patient's sex contributed less than $1 \%$, age less than 4\%, and WFNS score less than 5\%. Significant variance was explained, however, by information on the premorbid mental and neurological state. A history of psychiatric illness explained up to $10 \%$ of the variance in social functioning, role limitations-emotional, and mental health; a history of neurological conditions explained over $11 \%$ of the variance in general health perceptions and role limitations-physical. These findings partially support previous research showing that prior physical and mental health problems accounted for between 12\% and $15 \%$ of variance in mood disturbance, but no significant variance in functional outcomes. ${ }^{29}$ Our findings show an equivalent effect of psychiatric history on mental health, but no effect of neurological history. Another difference was the impact on functional outcomes: psychiatric history predicted social functioning (how much physical health or emotional problems have interfered with normal social activities) and role limitations-emotional (how much emotional problems have interfered with work and daily activities), whereas neurological history predicted role limitations-physical (how much physical health problems have interfered with work activities) and general health perceptions (rating of health in general).

These findings raise questions about whether a premorbid history of psychiatric or neurological problems compromises the recovery of patients with SAH and whether they therefore need additional support. To answer these questions we would need to know of course what their quality of life was like before the SAH to rule out the possibility that the deficits shown here simply reflect their premorbid health state. Without a premorbid measure we can only speculate whether the size of the deficits found are commensurate with how we might expect a psychiatric or neurological problem to impact someone's quality of life. This type of investigation would require a large sample of patients with SAH for whom detailed profiles were obtained about their prior medical history to allow comparisons to be made between their HRQOL scores and the norms obtained from equivalent patient groups. This type of analysis is outside the scope of the present study but warrants future investigation.

Although it is plausible to conclude that the reduced functioning in patients whose SOs are fearful of recurrence is the result of the SO's emotions, motivations, and/ or actions (possibly since diagnosis), the current study has a number of limitations that should be noted. First, the sample size was relatively small, and until they are replicated in other samples we cannot rule out the possibility that the results were unique, for some unexplained reason, to the cohort studied. The cross-sectional design used in this study also means that we need to be cautious in offering a causal interpretation. Although cross-sectional analyses are not unusual in research that has examined the interdependencies between a patient's quality of life and their caregiver's attitudes or emotions, ${ }^{18,33}$ further research in which a longitudinal design is used would be desirable. The causal interpretation would also be stronger if a randomized controlled trial were conducted to test whether an intervention designed to address, reduce, and manage the SO's fears can bring about improved patient quality of life over time.

\section{Conclusions}

The findings of this study suggest a need to offer greater support and assistance to the SOs of patients with $\mathrm{SAH}$. On average, their fears of SAH recurrence were inflated compared with those of the patients themselves, and importantly, these fears were associated with compromised functioning in certain domains of the patient's quality of life. It is therefore important not to neglect the emotions and anxieties of the SO as well as the patient early on in the treatment and rehabilitation process. If the source of their fears can be identified and addressed, the functioning of patients may potentially be improved. 


\section{Disclosure}

Dr. Schenk received support from the Clarke Lister Brain Hemorrhage Foundation. The authors report no conflict of interest concerning the materials or methods used in this study or the findings specified in this paper.

Author contributions to the study and manuscript preparation include the following. Conception and design: all authors. Acquisition of data: Noble. Analysis and interpretation of data: Covey. Drafting the article: Covey. Critically revising the article: all authors. Reviewed submitted version of manuscript: all authors. Approved the final version of the manuscript on behalf of all authors: Covey. Statistical analysis: Covey. Study supervision: Schenk.

\section{Acknowledgments}

The authors are most grateful to the patients and families who willingly participated in this research and to the Clarke Lister Brain Hemorrhage Foundation for their generous support. The authors also acknowledge the support of S. Baisch (Abteilung Psychologie, Kliniken Schmieder), who assisted with data collection, and W. R. Williams (Department of Psychology, Durham University), who provided advice on the statistical analysis.

\section{References}

1. Berry E: Post-traumatic stress disorder after subarachnoid haemorrhage. Br J Clin Psychol 37:365-367, 1998

2. Berry E, Jones RAC, West CGH, Brown JDK: Outcome of subarachnoid haemorrhage. An analysis of surgical variables, cognitive and emotional sequelae related to SPECT scanning. Br J Neurosurg 11:378-387, 1997

3. Boeve BF, Petersen RC: Neurobehavioral disorders after subarachnoid hemorrhage, in Yanagihara T, Piepgras DG, Atkinson JLD (eds): Subarachnoid Hemorrhage: Medical and Surgical Management. New York: Marcel Dekker, 1998, pp 159-216

4. Brilstra EH, Hop JW, Rinkel GJE: Quality of life after perimesencephalic haemorrhage. J Neurol Neurosurg Psychiatry 63:382-384, 1997

5. Buchanan KM, Elias LJ, Goplen GB: Differing perspectives on outcome after subarachnoid hemorrhage: the patient, the relative, the neurosurgeon. Neurosurgery 46:831-840, 2000

6. Cohen J: Statistical Power Analysis for the Behavioral Sciences, ed 2. Hillsdale, NJ: Erlbanm, 1988

7. David CA, Vishteh AG, Spetzler RF, Lemole M, Lawton MT, Partovi S: Late angiographic follow-up review of surgically treated aneurysms. J Neurosurg 91:396-401, 1999

8. Deane M, Pigott T, Dearing P: The value of the Short Form 36 score in the outcome assessment of subarachnoid haemorrhage. Br J Neurosurg 10:187-191, 1996

9. Drake CG: Report of World Federation of Neurological Surgeons Committee on a Universal Subarachnoid Hemorrhage Grading Scale. J Neurosurg 68:985-986, 1988

10. Field AP: Discovering Statistics Using SPSS, ed 3. London: Sage Publications, 2009

11. Hackett ML, Anderson CS: Health outcomes 1 year after subarachnoid hemorrhage: an international population-based study. Neurology 55:658-662, 2000

12. Hellawell DJ, Pentland B: Relatives' reports of long term problems following traumatic brain injury or subarachnoid haemorrhage. Disabil Rehabil 23:300-305, 2001

13. Hellawell DJ, Taylor R, Pentland B: Persisting symptoms and carers' views of outcome after subarachnoid haemorrhage. Clin Rehabil 13:333-340, 1999

14. Hop JW, Rinkel GJ, Algra A, van Gijn J: Quality of life in patients and partners after aneurysmal subarachnoid hemorrhage. Stroke 29:798-804, 1998

15. Hop JW, Rinkel GJE, Algra A, van Gijn J: Changes in func- tional outcome and quality of life in patients and caregivers after aneurysmal subarachnoid hemorrhage. J Neurosurg 95:957-963, 2001

16. Hütter BO: Neuropsychological Sequelae of Subarachnoid Haemorrhage and its Treatment. Vienna: Springer-Verlag, 2000

17. Katati MJ, Santiago-Ramajo S, Pérez-García M, MeersmansSánchez Jofré M, Vilar-Lopez R, Coín-Mejias MA, et al: Description of quality of life and its predictors in patients with aneurysmal subarachnoid hemorrhage. Cerebrovasc Dis 24: 66-73, 2007

18. Kim Y, Kashy DA, Wellisch DK, Spillers RL, Kaw CK, Smith TG: Quality of life of couples dealing with cancer: dyadic and individual adjustment among breast and prostate cancer survivors and their spousal caregivers. Ann Behav Med 35: 230-238, 2008

19. Kreitschmann-Andermahr I, Poll E, Hutter BO, Reineke A, Kristes S, Gilsbach JM, et al: Quality of life and psychiatric sequelae following aneurysmal subarachnoid haemorrhage: does neuroendocrine dysfunction play a role? Clin Endocrinol (Oxf) 66:833-837, 2007

20. Logue V, Durward M, Pratt RT, Piercy M, Nixon WL: The quality of survival after rupture of an anterior cerebral aneurysm. Br J Psychiatry 114:137-160, 1968

21. McKenna P, Neil-Dwyer G: Helping patients recover from subarachnoid haemorrhage. J Ment Health 2:315-320, 1993

22. McKenna P, Willison JR, Phil B, Lowe D, Neil-Dwyer G: Cognitive outcome and quality of life one year after subarachnoid haemorrhage. Neurosurgery 24:361-367, 1989

23. Mezue W, Mathew B, Draper P, Watson R: The impact of care on carers of patients treated for aneurysmal subarachnoid haemorrhage. Br J Neurosurg 18:135-137, 2004

24. Mohanty A, Das BS, Mukundan CR, Jamuna N: Cognitive outcome and quality of life after aneurysmal subarachnoid haemorrhage-part II. Quality of life. NIMHANS J 11:119 124, 1993

25. Molyneux A, Kerr R, Stratton I, Sandercock P, Clarke M, Shrimpton J, et al: International Subarachnoid Aneurysm Trial (ISAT) of neurosurgical clipping versus endovascular coiling in 2143 patients with ruptured intracranial aneurysms: a randomised trial. Lancet 360:1267-1274, 2002

26. Noble AJ, Baisch S, Mendelow AD, Allen L, Kane P, Schenk T: Posttraumatic stress disorder explains reduced quality of life in subarachnoid hemorrhage patients in both the short and long term. Neurosurgery 63:1095-1105, 2008

27. Noble AJ, Schenk T: Posttraumatic stress disorder in the family and friends of patients who have suffered spontaneous subarachnoid hemorrhage. Clinical article. J Neurosurg 109:1027-1033, 2008

28. Noble AJ, Schenk T: Which variables help explain the poor health-related quality of life after subarachnoid hemorrhage? A meta-analysis. Neurosurgery 66:772-783, 2010

29. Powell J, Kitchen N, Heslin J, Greenwood R: Psychosocial outcomes at three and nine months after good neurological recovery from aneurysmal subarachnoid haemorrhage: predictors and prognosis. J Neurol Neurosurg Psychiatry 72: 772-781, 2002

30. Pritchard C, Clapham L, Foulkes L, Lang DA, Neil-Dwyer G: Comparison of cohorts of elective and emergency neurosurgical patients: psychosocial outcomes of acoustic neuroma and aneurysmal sub arachnoid hemorrhage patients and carers. Surg Neurol 62:7-16, 2004

31. Pritchard C, Foulkes L, Lang DA, Neil-Dwyer G: Cost-benefit analysis of an integrated approach to reduce psychosocial trauma following neurosurgery compared with standard care: two-year prospective comparative study of enhanced specialist liaison nurse service for aneurysmal subarachnoid hemorrhage (ASAH) patients and carers. Surg Neurol 62:17-27, 2004 
32. Pritchard C, Foulkes L, Lang DA, Neil-Dwyer G: Psychosocial outcomes for patients and carers after aneurysmal subarachnoid haemorrhage. Br J Neurosurg 15:456-463, 2001

33. Romero C, Lindsay JE, Dalton WT, Nelson DV, Friedman LC: Husbands' perceptions of wives' adjustment to breast cancer: the impact on wives' mood. Psychooncology 17:237-243, 2008

34. Scheier MF, Carver CS: Dispositional optimism and physical well-being: the influence of generalized outcome expectancies on health. J Pers 55:169-210, 1987

35. Schuiling WJ, Rinkel GJ, Walchenbach R, de Weerd AW: Disorders of sleep and wake in patients after subarachnoid hemorrhage. Stroke 36:578-582, 2005

36. Schwartz TH, Solomon RA: Perimesencephalic nonaneurysmal subarachnoid hemorrhage: review of the literature. Neurosurgery 39:433-440, 1996

37. Soehle M, Chatfield DA, Czosnyka M, Kirkpatrick PJ: Predictive value of initial clinical status, intracranial pressure and transcranial Doppler pulsatility after subarachnoid haemorrhage. Acta Neurochir (Wien) 149:575-583, 2007

38. Stegen G, Freckmann N: Outcome and rehabilitation after aneurysmal subarachnoid haemorrhage. Zentralbl Neurochir 52:37-39, 1991

39. Toomela A, Pulver A, Tomberg T, Orasson A, Tikk A, Asser T: Possible interpretation of subjective complaints in patients with spontaneous subarachnoid haemorrhage. J Rehabil Med 36:63-69, 2004
40. Tsutsumi K, Ueki K, Usui M, Kwak S, Kirino T: Risk of recurrent subarachnoid hemorrhage after complete obliteration of cerebral aneurysms. Stroke 29:2511-2513, 1998

41. van der Schaaf IC, Wermer MJH, Velthuis BK, Buskens E, Bossuyt PMM, Rinkel GJE: Psychosocial impact of finding small aneurysms that are left untreated in patients previously operated on for ruptured aneurysms. J Neurol Neurosurg Psychiatry 77:748-752, 2006

42. Ware JE JR, Sherbourne CD: The MOS 36-Item Short-Form Health Survey (SF-36): I. Conceptual framework and item selection. Medical Care 30:473-483, 1992

43. Wermer MJH, Greebe P, Algra A, Rinkel GJE: Incidence of recurrent subarachnoid hemorrhage after clipping for ruptured intracranial aneurysms. Stroke 36:2394-2399, 2005

Manuscript submitted August 30, 2012.

Accepted May 14, 2013.

Please include this information when citing this paper: published online July 23, 2013; DOI: 10.3171/2013.5.JNS121688.

Address correspondence to: Judith Covey, Ph.D., Department of Psychology, Wolfson Research Institute of Health and Wellbeing, Durham University, Queen's Campus, Stockton-on-Tees TS17 6BH, United Kingdom.email: j.a.covey@durham.ac.uk. 